\title{
The alteration of serum soluble CD40 ligand levels in overt and subclinical hypothyroidism
}

\author{
Baris Akinci, ${ }^{1}$ Abdurrahman Comlekci, ${ }^{1}$ Serkan Yener, ${ }^{1}$ Tevfik Demir, ${ }^{1}$ \\ Firat Bayraktar, ${ }^{1}$ Faize Yuksel, ${ }^{2}$ Sena Yesil ${ }^{1}$
}

${ }^{1}$ Division of Endocrinology and Metabolism, ${ }^{2}$ Division of Haematology, Dokuz Eylul University Medical School, Department of Internal Medicine, Izmir, Turkey

\begin{abstract}
OBJECTIVE: There is controversy as to whether hypothyroidism increases cardiovascular risk. The effect of levothyroxine on the cardiovascular risk profile is also unclear. Recent studies suggest that there is evidence of inflammation and endothelial dysfunction in hypothyroidism. Soluble CD40 ligand (sCD40L) is a protein expressed mainly by activated platelets which have been found to be associated with cardiovascular events. The aim of our study was to investigate serum $\mathrm{SCD40L}$ levels and the effect of levothyroxine replacement on $\mathrm{SCD}$ 40L levels in overt and subclinical hypothyroidism. DESIGN: We assessed lipid profile, serum sCD40L and hsCRP levels in 21 overt and 22 subclinical hypothyroid age-matched female patients with chronic autoimmune thyroiditis at baseline and one month after achieving euthyroidism by levothyroxine replacement, and compared them with the data from 22 , age-matched, healthy controls. RESULTS: Overt and subclinical hypothyroid patients had decreased SCD40L levels compared to age-matched controls. The patients with subclinical hypothyroidism had slightly increased hsCRP levels, but the result was not statistically significant. In multiple regression analysis, $\mathrm{FT}_{3}$ and $\mathrm{FT}_{4}$ were found to be independent predictors of $\mathrm{SCD} 40 \mathrm{~L}$ levels. After levothyroxine replacement, serum $S C D 40 \mathrm{~L}$ levels increased significantly in the patients with overt hypothyroidism. Although an increase was also observed in the subclinical hypothyroid group, it was not statistically significant. Levothyroxine replacement had no significant effect on hsCRP levels in the patients with overt hypothyroidism. However, the subjects with subclinical hypothyroidism showed a significant reduction in hsCRP levels after levothyroxine. CONCLUSION: The values of SCD40L and hsCRP in our study suggest that inflammatory pathways are complex and may be affected by different factors in hypothyroidism.
\end{abstract}

Key words: Cardiovascular risk, CD40, Inflammation, Levothyroxine, Thyroid dysfunction 


\section{INTRODUCTION}

Hypothyroidism is believed to implicate increased risk for atherosclerotic disease. ${ }^{1}$ However, the results of prospective studies conducted in patients with hypothyroidism are controversial. The Rotterdam Study ${ }^{2}$ has shown that subclinical hypothyroidism is associated with aortic atherosclerosis and myocardial infarction in elderly women. Several studies suggest that levothyroxine replacement may improve the signs of early atherosclerosis such as carotid artery intima media thickening, ${ }^{3}$ subclinical inflammation ${ }^{4}$ and hemostatic defects ${ }^{5,6}$ in patients with overt and subclinical hypothyroidism. On the other hand, the Whickham survey ${ }^{7}$ has found no relationship between initial TSH levels and the subsequent development of ischemic heart disease over 20 years of follow-up.

Soluble CD40 ligand (sCD40L) is the soluble form of the cell bound transmembrane protein CD40L that is released from $\mathrm{T}$ cells, activated platelets, smooth muscle cells and endothelial cells. ${ }^{8}$ It has been shown that $\mathrm{SCD} 40 \mathrm{~L}$ is also expressed by the coronary atheroma. As sCD40L binds with CD40, it leads to the release of procoagulant and atherogenic substances and enzymes which may result in unstable atherosclerotic plaque development. ${ }^{8,9}$ There is evidence that increased levels of SCD40L occur in acute coronary syndrome and that elevated sCD40L levels predict an increased cardiovascular risk in healthy subjects. ${ }^{10}$

The purpose of our study was to determine serum sCD40L levels in overt and subclinical hypothyroid patients with chronic autoimmune thyroiditis and to examine the effect of levothyroxine treatment on sCD40L levels.

\section{MATERIALS AND METHODS}

\section{Subjects}

Twenty-one overt hypothyroid (range 25-62 years) and 22 subclinical hypothyroid (range 21-74 years) female patients with chronic autoimmune thyroiditis, and 22 female controls (range 33-70 years) were enrolled in the study. Overt hypothyroidism was defined as TSH $>5 \mathrm{mIU} / \mathrm{L}$ and free thyroid hormones below normal levels. Subclinical hypothyroidism was defined as TSH $>5 \mathrm{mIU} / \mathrm{L}$ with normal free thyroid hormone levels. The control group consisted of age-matched euthyroid healthy hospital staff.

Exclusion criteria were diabetes, known atherosclerotic disease, metabolic syndrome (according to the National Cholesterol Education Program Adult Treatment Panel III), cardiac, renal, hepatic and other systemic diseases, morbid obesity, familial hyperlipidemia and history of malignancy. Patients also excluded from the study were those taking betablockers, antihypertensive, anti-hyperlipidemic agents, acetylsalicylic acid, antihistamines, multivitamins and corticosteroids. Patients with alcohol consumption and current smokers as well as women on oral contraceptives or hormonal replacement therapy were also excluded. Informed consent was obtained in all cases, and the study was approved by the local ethics committee of Dokuz Eylul University.

The patients were treated with peroral levothyroxine, treatment starting with $25 \mu \mathrm{g} /$ day. TSH was measured every 4 weeks to adjust the ${\mathrm{L}-\mathrm{T}_{4}}_{4}$ dose. All patients were revaluated 4 weeks after restoration of euthyroidism. Blood samples were collected, first at baseline and one month after successful replacement therapy with levothyroxine (range of daily levothyroxine dose to maintain euthyroidism was 50 to $250 \mu \mathrm{g} /$ day).

\section{Methods}

Height $(\mathrm{m})$, weight $(\mathrm{kg})$, waist $(\mathrm{cm})$ and hip $(\mathrm{cm})$ circumferences were measured under fasting conditions with subjects in light clothing and without shoes. Height was measured to the nearest centimeter using a rigid stadiometer. Weight was measured to the nearest $0.1 \mathrm{~kg}$ using a calibrated balance scale. Waist circumference (WC) was measured with a steel measuring tape at the high point of the iliac crest to the nearest $0.1 \mathrm{~cm}$ at the end of normal expiration. Hip circumference (HC) was the maximal circumference over the buttocks as seen from the side. All measurements were taken with the subject standing upright. Body mass index (BMI) was calculated as the weight in kilograms divided by the height in meters squared. Waist-hip ratio (WHR) was calculated by dividing waist circumference by hip circumference. Blood pressure was measured using a sphygmomanometer in the sitting position after $5 \mathrm{~min}$ rest. Two measurements were taken on the right arm and the 
average of these two measurements was used for all analyses.

Fasting blood samples were taken during hypothyroid status and 4 weeks after euthyroidism was achieved. Blood samples were obtained after a resting period of $30 \mathrm{~min}$ between 08.00 and 09:00 from the cannulated antecubital vein. Serum was obtained by centrifugation at $2000 \mathrm{~g}$ for 15 minutes at $+4^{\circ} \mathrm{C}$. The plasma samples were stored at $-80^{\circ} \mathrm{C}$ until analysis.

Serum sCD40L concentrations were assayed using an enzyme-linked immunosorbent assay (ELISA) kit from Biosource (Nivelles, Belgium). The sensitivity was $0.095 \mathrm{ng} / \mathrm{ml}$. Intraassay and interassay coefficients of variation were 4 and $6.8 \%$, respectively. Serum high sensitive C-reactive protein (hsCRP) was measured by Cobas Integra 400 autoanalyzer using a particle enhanced turubidimetric assay (Roche Diagnostics, Indianapolis, USA). The sensitivity of hs-CRP was $0.11 \mathrm{mg} / \mathrm{L}$. The intraassay and interassay coefficients of variation were 1.34 and 5.70, respectively. Triglycerides, total cholesterol and HDL cholesterol were measured by Roche/Hitachi D/P Modular System Autoanalyzer (Roche Diagnostics, Basel, Switzerland). LDL cholesterol was calculated by the Friedewald equation method. Free T3 (normal range 1.8-4.2 $\mathrm{pg} / \mathrm{mL}$ ) and free T4 (normal range 0.8-1.9 ng/dL) levels were determined using an immunoassay (Immulite 2000, Diagnostic Products Corporation, Los Angeles, USA). Anti-thyroid peroxidase antibody (Anti TPO), anti-thyroglobulin antibody (Anti Tg) and serum TSH levels were measured using solid phase chemiluminescent immunometric assay (Immulite 2000, Diagnostic Products Corporation, Los Angeles, USA).

\section{Statistical analysis}

The data were analyzed by SPSS 11.0 for Windows. The Kruskal-Wallis test was used for the initial comparison. Differences between the groups were assessed using the Mann-Whitney $U$ test as a post hoc test. The Wilcoxon signed rank test was used for comparison of treatment effects on variables. Correlation analyses were conducted by Spearman's test. P value of $<0.05$ (two-tailed) was statistically significant. Data are expressed as median and 25-75 percentiles.

\section{RESULTS}

Median age of the overt hypothyroid, subclinical hypothyroid and control groups were $48,47.5$ and 47 years, respectively. There was no significant difference between overt hypothyroid, subclinical hypothyroid and control groups regarding age. Although hypothyroid patients, and particularly the overt hypothyroid, had higher BMI and waist and hip circumference, the results were not statistically significant. Baseline systolic and diastolic blood pressures were comparable (Table 1).

Total cholesterol, LDL and HDL cholesterol levels were higher in the overt hypothyroid group when compared with the subclinical hypothyroid group and also with the control group ( $p<0.001$ for total cholesterol, vs. control group; $p<0.001$ for LDL cholesterol, vs. control group; $p=0.001$ for HDL cholesterol, vs. control group; $p<0.001$ for total cholesterol, vs. subclinical hypothyroid group, $\mathrm{p}<0.001$ for LDL cholesterol, vs. subclinical hypothyroid group, $\mathrm{p}=0.035$ for HDL cholesterol, vs. subclinical hypothyroid group). There was no statistically significant difference in lipid levels between the subclinical hypothyroid patients and the controls (Table 1).

The overt and subclinical hypothyroid patients had decreased baseline sCD40L levels compared to controls ( $p<0.001$, Table- 1 ). Although the overt hypothyroid patients had lower serum sCD40L levels than the subclinical hypothyroid subjects, the difference was not statistically significant $(p=0.239)$. No statistically significant differences were observed in terms of hsCRP levels among overt hypothyroid, subclinical hypothyroid patients and controls $(\mathrm{p}=0.062)$. However, the subjects with subclinical hypothyroidism had slightly elevated, though statistically non-significant hsCRP levels compared to controls.

Total cholesterol, LDL-cholesterol and HDLcholesterol levels were decreased by levothyroxine replacement in the patients with overt hypothyroidism. As a result of the levothyroxine replacement, total cholesterol/HDL and LDL/HDL ratios were also decreased in the overt hypothyroid group. Levothyroxine replacement therapy caused no significant change in lipid parameters among the patients with subclinical hypothyroidism (Table 2). 
Table 1. Baseline characteristic of hypothyroid patients and controls.

\begin{tabular}{|c|c|c|c|c|}
\hline & $\begin{array}{l}\text { Overt Hypothyroid } \\
(\mathrm{n}=21)\end{array}$ & $\begin{array}{l}\text { Subclinical Hypothyroid } \\
\qquad(\mathrm{n}=\mathbf{2 2})\end{array}$ & $\begin{array}{c}\text { Controls } \\
(n=22)\end{array}$ & P value \\
\hline Age & $48(41-55)$ & $47.5(36-60.5)$ & $47(41-51.5)$ & 0.897 \\
\hline Weight $(\mathrm{kg})$ & $73(67-81)$ & $68.5(59-76.25)$ & $68(60.75-76.25)$ & 0.265 \\
\hline $\operatorname{BMI}\left(\mathrm{kg} / \mathrm{m}^{2}\right)$ & $29.24(23.68-32.33)$ & $26.76(24.5-30.06)$ & $26.98(23.27-30.34)$ & 0.74 \\
\hline Waist $(\mathrm{cm})$ & $85(76.5-99.5)$ & $84.5(71.25-91.5)$ & $82.5(71-86.25)$ & 0.202 \\
\hline Hip (cm) & $107(101-117.5)$ & $103.5(89.8-113)$ & $99.5(90.5-107)$ & 0.072 \\
\hline WHR & $0.8(0.75-0.84)$ & $0.79(0.75-0.84)$ & $0.8(0.76-0.83)$ & 0.885 \\
\hline Systolic BP (mmHg) & $120(110-120)$ & $120(110-120)$ & $120(110-120)$ & 0.949 \\
\hline Diastolic BP (mmHg) & $70(70-80)$ & $70(70-80)$ & $75(70-80)$ & 0.310 \\
\hline FT3 $(\mathrm{pg} / \mathrm{ml})$ & $2.03(1-2.38)^{\dagger \ddagger}$ & $2.54(2.17-3.08)$ & $2.8(2.53-2.97)$ & $<0.001^{*}$ \\
\hline FT4 (ng/dl) & $0.62(0.4-0.75)^{\dagger \dagger}$ & $1.23(1.06-1.34)^{\dagger}$ & $1.35(1.24-1.5)$ & $<0.001^{*}$ \\
\hline TSH (mIU/L) & $52.6(37.14-122))^{\dagger \dagger}$ & $11.25(7.9-27.8)^{\dagger}$ & $1.13(0.86-1.99)$ & $<0.001^{*}$ \\
\hline Total Cholesterol (mg/dl) & $264(218-331)^{\dagger \dagger}$ & $201(173-214)$ & $193(172-204)$ & $<0.001^{*}$ \\
\hline Triglyceride (mg/dl) & $123(70-156)$ & $112(87-144)$ & $108(68-171)$ & 0.878 \\
\hline LDL Cholesterol (mg/dl) & $156(135-218)^{\dagger \dagger}$ & $113(100-127)$ & $110(90-124)$ & $0.001^{*}$ \\
\hline HDL Cholesterol (mg/dl) & $67(56-88)^{\dagger \ddagger}$ & $60(53-69)$ & $55(47-59)$ & $0.002^{*}$ \\
\hline $\mathrm{TC} / \mathrm{HDL}$ & $3.96(3.16-4.78)$ & $3.37(2.81-3.88)$ & $3.3(2.87-4.52)$ & 0.168 \\
\hline $\mathrm{LDL} / \mathrm{HDL}$ & $2.55(1.89-3.2)$ & $1.99(1.55-2.26)$ & $1.97(1.62-2.9)$ & 0.073 \\
\hline hsCRP (mg/L) & $1.01(0.61-2.26)$ & $2.24(1.3-4.66)$ & $1.85(0.87-2.25)$ & 0.062 \\
\hline $\mathrm{sCD} 40 \mathrm{~L}(\mathrm{ng} / \mathrm{ml})$ & $6.98(4.73-7.72)^{\dagger}$ & $8.24(4.46-10.35)^{\dagger}$ & $9.86(8.75-12.23)$ & $<0.001^{*}$ \\
\hline
\end{tabular}

Data are expressed as median and 25-75 percentiles. Expressed $\mathrm{p}$ values were calculated using Kruskal-Wallis test, ${ }^{*} \mathrm{p}<0.05$; ${ }^{\dagger} \mathrm{vs}$. control group, $\mathrm{p}<0.05 ;{ }^{\ddagger}$ vs. subclinical hypothyroid group, $\mathrm{p}<0.05$.

BMI: Body mass index, BP: Blood pressure, $\mathrm{FT}_{3}$ : Free 3.5.3'-triiodothyronine, $\mathrm{FT}_{4}$ : Free thyroxine, HDL: High density lipoprotein, hsCRP: High sensitive C-reactive protein, LDL: Low density lipoprotein, sCD40L: Soluble CD40 ligand, TC: Total cholesterol, TSH: Thyroid stimulating hormone, WHR: Waist hip ratio.

Conversion factor $(\mathrm{CF})$ for lipid levels $(\mathrm{CF} \times \mathrm{C}=\mathrm{SI}): 0.02586$

$\mathrm{CF}$ for $\mathrm{FT}_{3}(\mathrm{CF} \times \mathrm{C}=\mathrm{SI}): 1.54, \mathrm{CF}$ for $\mathrm{FT}_{4}(\mathrm{CF} \times \mathrm{C}=\mathrm{SI}): 12.9$.

Table 2. The values of hsCRP, sCD40L and lipid levels before and after levothyroxine replacement therapy.

\begin{tabular}{|c|c|c|c|c|c|c|}
\hline & $\begin{array}{c}\text { Overt } \\
\text { Before }\end{array}$ & $\begin{array}{l}\text { Overt } \\
\text { After }\end{array}$ & $\begin{array}{l}\text { P value } \\
\text { (Overt) }\end{array}$ & $\begin{array}{c}\text { Subclinical } \\
\text { Before }\end{array}$ & $\begin{array}{c}\text { Subclinical } \\
\text { After }\end{array}$ & $\begin{array}{c}\text { P value } \\
\text { (Subclinical) }\end{array}$ \\
\hline Total Cholesterol (mg/dl) & $264(218-331) \dagger$ & $206(182-226)$ & $<0.001 \dagger$ & $201(173-214)$ & $188(169-206)$ & 0.330 \\
\hline Triglyceride $(\mathrm{mg} / \mathrm{dl})$ & $123(70-156)$ & $94(67-122)$ & 0.145 & $112(87-144)$ & $110(86-153)$ & 0.073 \\
\hline LDL Cholesterol (mg/dl) & $156(135-218) \dagger$ & $120(106-135)$ & $0.001 \dagger$ & $113(100-127)$ & $109(89-128)$ & 0.181 \\
\hline HDL Cholesterol (mg/dl) & $67(56-88) \dagger$ & $59(52-69)$ & $0.001 \dagger$ & $60(53-69)$ & $55(51-67)$ & 0.191 \\
\hline TC/HDL & $3.96(3.16-4.78) \dagger$ & $3.29(2.86-4.03)$ & $0.01 \dagger$ & $3.37(2.81-3.88)$ & $3.4(2.74-3.89)$ & 0.661 \\
\hline LDL/HDL & $2.55(1.89-3.2) \dagger$ & $1.94(1.64-2.58)$ & $0.021 \dagger$ & $1.99(1.55-2.26)$ & $2.07(1.4-2.3)$ & 0.783 \\
\hline $\mathrm{hsCRP}(\mathrm{mg} / \mathrm{L})$ & $1.01(0.61-2.26)$ & $1.45(0.68-3.59)$ & 0.266 & $2.24(1.3-4.66) \dagger$ & $1.6(0.86-2.59)$ & $0.033 \dagger$ \\
\hline $\mathrm{sCD} 40 \mathrm{~L}(\mathrm{ng} / \mathrm{ml})$ & $6.98(4.73-7.72) \dagger$ & $9.41(5.88-10.29)$ & $0.03 \dagger$ & $8.24(4.46-10.35)$ & $9.33(6.09-11.43)$ & 0.115 \\
\hline
\end{tabular}

Data are expressed as median and 25-75 percentiles, $\mathrm{p}$ values were calculated using Wilcoxon paired test.

HDL: High density lipoprotein, hsCRP: High sensitive C-reactive protein, LDL: Low density lipoprotein, sCD40L: Soluble CD40 ligand, TC: Total cholesterol.

† before vs. after levothyroxine replacement, $\mathrm{p}<0.05$. 
Serum SCD40L levels were found to be elevated by levothyroxine in the patients with overt hypothyroidism ( $p<0.001$ ). There was, however, no significant change in $\mathrm{SCD} 40 \mathrm{~L}$ levels in the subclinical hypothyroid patients when they achieved euthyroidism. Restoration of euthyroidism by levothyroxine replacement had no significant effect on hsCRP levels in the overt hypothyroid group. However, the patients with subclinical hypothyroidism showed a significant reduction in hsCRP levels after levothyroxine treatment (Table 2).

Serum SCD40L was found to be positively correlated with $\mathrm{FT}_{3}(\mathrm{r}=0.3, \mathrm{p}=0.015)$ and $\mathrm{FT}_{4}(\mathrm{r}=0.441$, $\mathrm{p}<0.001)$, and negatively correlated with TSH levels $(\mathrm{r}=-0.455, \mathrm{p}<0.001$, Table 3$)$. The serum hsCRP level was observed to be negatively correlated with serum HDL cholesterol $(\mathrm{r}=-0.316, \mathrm{p}=0.01$, Table 3). Baseline $\mathrm{FT}_{3}$ and $\mathrm{FT}_{4}$ were found to have independent effects on $\mathrm{SCD} 40 \mathrm{~L}$ levels in multiple regression analysis after adjustment for age, BMI, total cholesterol, LDL cholesterol and HDL cholesterol $\mathrm{FT}_{3}\left(\right.$ model $\mathrm{r}^{2}=0.112$, beta $=0.363, \mathrm{p}=0.033$ for $\mathrm{FT}_{3}$, and model $\mathrm{r}^{2}=0,215$, beta $=0.608, \mathrm{p}=0.01$ for $\mathrm{FT}_{4}$, respectively, Table 4). No independent variable was found to affect hsCRP levels after adjustment for age and BMI. Neither serum sCD40L nor hsCRP levels were associated with anthropometric measurements and menopausal status.

\section{DISCUSSION}

The present study showed that patients with overt and subclinical hypothyroidism associated with chronic autoimmune thyroiditis had decreased serum levels of sCD40L. Circulating levels of free thyroid hormones were independent predictors of serum CD40L levels, whereas serum TSH had no significant effect on these levels after adjustment for age, BMI and serum lipids. In the patients with overt hypothyroidism, sCD40L levels increased after levothyroxine replacement. A slight increase was also observed in the subclinical hypothyroid group, but it was not statistically significant. No association was found between $\mathrm{SCD} 40 \mathrm{~L}$ and hsCRP levels. Serum hsCRP levels were nearly com-

Table 4. Multiple regression analysis showing factors affecting serum $\mathrm{SCD} 40 \mathrm{~L}$ levels.

a.

\begin{tabular}{lcc}
\hline & $\begin{array}{c}\text { Standardized Coefficients } \\
\text { Beta }\end{array}$ & P value \\
\hline FT3 & 0.363 & $0.033 \dagger$ \\
Age & 0.125 & 0.382 \\
BMI & -0.049 & 0.749 \\
Total Cholesterol & 0.421 & 0.489 \\
LDL Cholesterol & -0.121 & 0.464 \\
HDL Cholesterol & -0.203 & 0.717 \\
\hline
\end{tabular}

BMI: Body mass index, $\mathrm{FT}_{3}$ : Free 3.5.3'-triiodothyronine, $\mathrm{HDL}$ : High density lipoprotein, LDL: Low density lipoprotein; model $\mathrm{r}^{2}=0.112 ;{ }^{\dagger} \mathrm{p}<0.05$

b.

\begin{tabular}{lcc}
\hline & $\begin{array}{c}\text { Standardized Coefficients } \\
\text { Beta }\end{array}$ & P value \\
\hline FT4 & 0.608 & $0.01 \dagger$ \\
Age & -0.048 & 0.730 \\
BMI & 0.081 & 0.574 \\
Total Cholesterol & 0.223 & 0.691 \\
LDL Cholesterol & 0.161 & 0.762 \\
HDL Cholesterol & -0.049 & 0.755 \\
\hline
\end{tabular}

BMI: Body mass index, $\mathrm{FT}_{4}$ : Free thyroxine, HDL: High density lipoprotein, LDL: Low density lipoprotein; model $\mathrm{r}^{2}=0.112 ;{ }^{\dagger}$ $\mathrm{p}<0.05$.

Table 3. Spearman correlation coefficients between serum sCD40L, hsCRP and thyroid hormones, TSH and lipid parameters.

\begin{tabular}{lccccccc}
\hline & $\mathbf{F T}_{3}$ & $\mathbf{F T}_{\mathbf{4}}$ & TSH & $\begin{array}{c}\text { Total } \\
\text { Cholesterol }\end{array}$ & Triglyceride & $\begin{array}{c}\text { LDL } \\
\text { Cholesterol }\end{array}$ & $\begin{array}{c}\text { HDL } \\
\text { Cholesterol }\end{array}$ \\
\hline sCD40L r & 0.3 & 0.441 & -0.455 & -0.09 & 0.178 & -0.106 & -0.181 \\
$\mathrm{p}$ & $0.015^{\dagger}$ & $<0.001^{\dagger}$ & $<0.001^{\dagger}$ & 0.475 & 0.155 & 0.402 & 0.15 \\
$\mathrm{hSCRP} \mathrm{r}$ & 0.135 & 0.126 & -0.120 & -0.127 & 0.130 & -0.171 & -0.316 \\
$\mathrm{p}$ & 0.282 & 0.319 & 0.343 & 0.314 & 0.303 & 0.173 & $0.01^{\dagger}$ \\
\hline
\end{tabular}

$\mathrm{FT}_{3}$ : Free 3.5.3'-triiodothyronine, $\mathrm{FT}_{4}$ : Free thyroxine, HDL: High density lipoprotein, hsCRP: High sensitive C-reactive protein, LDL: Low density lipoprotein, sCD40L: Soluble CD40 ligand, TSH: Thyroid stimulating hormone, ${ }^{\dagger} \mathrm{p}<0.05$. 
parable in the overt hypothyroid and control groups. Although the subclinical hypothyroid patients had higher hsCRP levels than the controls, the difference was not statistically significant. However, levothyroxine replacement resulted in a significant reduction of hsCRP in the subclinical hypothyroid group.

Recent evidence suggests an important role for inflammation in all phases of the atherosclerotic process. ${ }^{11}$ Studies have demonstrated a clear relationship between inflammation markers and risk for cardiovascular events. ${ }^{10,11}$ Elevated levels of inflammatory markers, such as C-reactive protein (CRP), have been found to be directly related to the risk of myocardial infarction. ${ }^{12}$ CRP is a widely used inflammatory biomarker to assess cardiovascular risk in healthy subjects as well as in people with various disorders. It has been shown that serum CRP is a marker of systemic inflammation and a strong predictor of future cardiovascular events. ${ }^{13} \mathrm{CD} 40$ ligand is a transmembrane protein related to tumor necrosis factor alpha. Elevated SCD40L levels have been found to be associated with higher risk for cardiovascular events. ${ }^{8,10}$

It is still unclear whether hypothyroidism increases cardiovascular risk. Recent studies suggest that hypothyroidism even in the subclinical state may be associated with atherosclerotic disease. ${ }^{1,2}$ However, the reported incidence of angina pectoris and myocardial infarction in untreated hypothyroidism is small. ${ }^{14}$ No relationship was found between baseline TSH levels and the risk of ischemic heart disease over 20 years of follow-up in the Whickham survey. ${ }^{7}$ Moreover, in a recent study Alevizaki et a ${ }^{15}$ showed a significant association of hypothyroidism with improved outcome and longer survival of patients admitted for acute stroke. Several epidemiological data also support this notion. In a population-based study in the United Kingdom, people with slightly elevated TSH have been found to have better survival. ${ }^{16}$ In another epidemiological study, both mild as well as more severe untreated hypothyroidism was found to be associated with better survival. ${ }^{17}$

On the other hand, other studies provide evidence for endothelial dysfunction and elevated levels of several inflammatory markers in hypothyroidism..$^{1,3,4}$ Increased hs-CRP levels have been reported in sub- clinical hypothyroidism. ${ }^{18}$ Ozcan et $\mathrm{al}^{4}$ found a significant reduction of serum CRP levels after treatment with levothyroxine in subclinical hypothyroidism. We also found a slight elevation in hsCRP levels among people with subclinical hypothyroidism. As our study population was small, the difference between subclinical hypothyroid and control groups did not attain statistical significance. However, the reduction of hsCRP after levothyroxine was significant in the subclinical hypothyroid group.

Our findings, including alterations in SCD40L and hsCRP levels in hypothyroidism before and after levothyroxine replacement therapy, seem to be conflicting. However, it is possible that serum levels of sCD40L and hsCRP may be affected by different factors in hypothyroidism. Since $\mathrm{SCD} 40 \mathrm{~L}$ is a cytokine mainly derived from activated platelets, impairment in platelet functions may lead to low sCD40L levels in hypothyroidism. Myrup et $\mathrm{al}^{19}$ have reported that bleeding time is prolonged and maximal agglutination velocity is decreased in hypothyroidism. Resolution of the platelet functions after achieving euthyroidism has been also noted in this study. Palareti et $\mathrm{al}^{20}$ showed impaired platelet reactivity to adrenalin and collagen in hypothyroid subjects after total thyroidectomy. They found that impaired platelet activity was corrected by substitutive therapy with L-thyroxine at clinically effective doses. In another study, platelet adhesiveness has been found to be suppressed in hypothyroidism but has increased to normal value after thyroid hormone replacement. ${ }^{21}$ Platelet hypoaggregability, ${ }^{22}$ haemostatic defects in response to aspirin, ${ }^{23}$ platelet function defects potentiated by methyldopa ${ }^{24}$ and low platelet adhesiveness ${ }^{25}$ have been reported in hypothyroidism.

In conclusion, our results demonstrate that serum sCD40L levels are decreased in chronic autoimmune thyroiditis with both overt and subclinical hypothyroidism. Levothyroxine replacement resulted in a significant increase of sCD40L levels among people with overt hypothyroidism. However, our study included a relatively small number of patients and could not provide data on an effect of these alterations on cardiovascular events. The underlying mechanism of decreased SCD40L levels in hypothyroidism and their relationship to other markers of platelet activation and inflammation should be further investigated. 


\section{REFERENCES:}

1. Cappola AR, Ladenson PW, 2003 Hypothyroidism and atherosclerosis. J Clin Endocrinol Metab 88: 2438-2444.

2. Hak AE, Pols HA, Visser TJ, Drexhage HA, Hofman A, Witteman JC, 2000 Subclinical hypothyroidism is an independent risk factor for atherosclerosis and myocardial infarction in elderly women: the Rotterdam Study. Ann Intern Med 132: 270-278.

3. Monzani F, Caraccio N, Kozakowa M, et al, 2004 Effect of levothyroxine replacement on lipid profile and intima-media thickness in subclinical hypothyroidism: a double-blind, placebo-controlled study. J Clin Endocrinol Metab 89: 2099-2106.

4. Ozcan O, Cakir E, Yaman H, et al, 2005 The effects of thyroxine replacement on the levels of serum asymmetric dimethylarginine (ADMA) and other biochemical cardiovascular risk markers in patients with subclinical hypothyroidism. Clin Endocrinol (Oxf) 63: 203-206.

5. Gullu S, Sav H, Kamel N, 2005 Effects of levothyroxine treatment on biochemical and hemostasis parameters in patients with hypothyroidism. Eur J Endocrinol 152: 355-361.

6. Akinci B, Comlekci A, Ali Ozcan M, et al, 2007 Elevated Thrombin Activatable Fibrinolysis Inhibitor (TAFI) Antigen Levels in Overt and Subclinical Hypothyroid Patients Were Reduced by Levothyroxine Replacement. Endocr J 54: 45-52.

7. Vanderpump MP, Tunbridge WM, French JM, et al, 1996 The development of ischemic heart disease in relation to autoimmune thyroid disease in a 20 -year follow-up study of an English community. Thyroid 6: 155-160.

8. Schonbeck U, Libby P, 2001 CD40 signaling and plaque instability. Circ Res 89: 1092-1103.

9. Mach F, Schonbeck U, Sukhova GK, et al, 1997 Functional CD40 ligand is expressed on human vascular endothelial cells, smooth muscle cells, and macrophages: implications for CD40-CD40 ligand signaling in atherosclerosis. Proc Natl Acad Sci U S A 94: 1931-1936.

10. Schonbeck U, Varo N, Libby P, Buring J, Ridker PM, 2001 Soluble CD40L and cardiovascular risk in women. Circulation 104: 2266-2268.

11. Ross R, 1999 Mechanisms of Disease: AtherosclerosisAn Inflammatory Disease. N Engl J Med 340: 115-126.

12. Miller M, Zhan M, Havas S, 2005 High attributable risk of elevated $\mathrm{C}$-reactive protein level to conventional coronary heart disease risk factors: the Third National Health and Nutrition Examination Survey. Arch Intern Med 165: 2063-2068.
13. Pearson TA, Mensah GA, Alexander RW, et al, 2003 Markers of inflammation and cardiovascular disease: application to clinical and public health practice: A statement for healthcare professionals from the Centers for Disease Control and Prevention and the American Heart Association. Circulation 107: 499-511.

14. Roos A, Zoet-Nugteren SK, Berghout A, 2005 Evaluation of cardiac ischaemia in cardiac asymptomatic newly diagnosed untreated patients with primary hypothyroidism. Neth J Med 63: 97-102.

15. Alevizaki M, Synetou M, Xynos K, Alevizaki CC, Vemmos $\mathrm{KN}, 2006$ Hypothyroidism as a protective factor in acute stroke patients. Clin Endocrinol (Oxf) 65: 369-372.

16. Parle JV, Maisonneuve P, Sheppard MC, Boyle P, Franklyn JA, 2001 Prediction of all-cause and cardiovascular mortality in elderly people from one low serum thyrotropin result: a 10-year cohort study. Lancet 358: 861-865.

17. Gussekloo J, van Exel E, de Craen AJ, Meinders AE, Frolich M, Westendorp RG, 2004 Thyroid status, disability and cognitive function, and survival in old age. Jama 292: 2591-2599.

18. Christ-Crain M, Meier C, Guglielmetti M, et al, 2003 Elevated C-reactive protein and homocysteine values: cardiovascular risk factors in hypothyroidism? A crosssectional and a double-blind, placebo-controlled trial. Atherosclerosis 166: 379-386.

19. Myrup B, Bregengard C, Faber J, 1995 Primary haemostasis in thyroid disease. J Intern Med 238: 59-63.

20. Palareti G, Biagi G, Legnani C, et al, 1989 Association of reduced factor VIII with impaired platelet reactivity to adrenalin and collagen after total thyroidectomy. Thromb Haemost 62: 1053-1056.

21. Hellem AJ, Segaard E, Solem JH,1975 The adhesiveness of human blood platelets and thyroid function. Acta Med Scand 197: 15-17.

22. O'Regan S, Fong JS, 1978 Platelet hypoaggregability in hypothyroid rats. Proc Soc Exp Biol Med 158: 575-577.

23. Zeigler ZR, Hasiba U, Lewis JH, Vagnucci AH, West VA, Bezek EA, 1986 Hemostatic defects in response to aspirin challenge in hypothyroidism. Am J Hematol 23: 391-399.

24. Zeigler Z, Hasiba U, Lewis J, Vagnucci A, West V, Bezek E, 1984 Exaggeration of defective platelet function by methyldopa in hypothyroidism. Am J Hematol 17: 209215.

25. Edson JR, Fecher DR, Doe RP, 1975 Low platelet adhesiveness and other hemostatic abnormalities in hypothyroidism. Ann Intern Med 82: 342-346. 